\title{
Up-regulation of HLA class I antigen expression and antigen-specific CTL response in cervical cancer cells by the demethylating hydralazine and the histone deacetylase inhibitor valproic acid
} María de Lourdes Mora-García*1, Alfonso Duenas-González², Jorge Hernández-Montes ${ }^{1}$, Benny Weiss-Steider ${ }^{1}$, Edelmiro Santiago-Osorio ${ }^{3}$, Vianney Francisco Ortíz-Navarrete ${ }^{4}$, Víctor Hugo Rosales ${ }^{4}$, David Cantú ${ }^{2}$, Marcela Lizano-Soberón ${ }^{2}$ and Alberto Monroy-García ${ }^{5}$

Address: ${ }^{1}$ Laboratorio de Inmunobiología, Unidad de Investigación en Diferenciación Celular y Cáncer. FES-Zaragoza, UNAM, México, ${ }^{2}$ Unidad de Investigación Biomédica en Cáncer, Instituto de Investigaciones Biomédicas, UNAM, Instituto Nacional de Cancerología, México, ${ }^{3}$ Laboratorio de Biología Molecular del Cáncer, Unidad de Investigación en Diferenciación Celular y Cáncer, FES-Zaragoza, UNAM, México, ${ }^{4}$ Departamento de Biomedicina, CINVESTAV, IPN, México and ${ }^{5}$ Unidad de Investigación Médica en Enfermedades Oncológicas. IMSS, CMN SXXI, México

* Corresponding author

from 24th Annual Meeting of the National Cancer Institute of Mexico

Mexico City, Mexico. 14-17 February 2007

Published: 5 February 2007

BMC Cancer 2007, 7(Suppl I):AI2 doi:10.1 I86/I47I-2407-7-SI-A12

This article is available from: http://www.biomedcentral.com/I47I-2407/7/SI/AI2

(c) 2007 Mora-García et al; licensee BioMed Central Ltd.

\section{Background}

DNA hypermethylation and histone deacetylation are epigenetic events that contribute to the absence or downregulated expression of different components of the tumor recognition complex. These events affect the processing and presentation of antigenic peptides to CTLs by HLA class I molecules. In this work we evaluated the effect of the DNA hypomethylating agent hydralazine $(\mathrm{H})$ and the histone deacetylase inhibitor valproic acid (VA), on the expression of HLA class I molecules and in the antigenspecific immune recognition of cervical cancer cells.

\section{Materials and methods}

Cell lines C33A (HPV-), CaSki (HPV-16+) and MS751 (HPV-18+) were treated with hydralazine and valproic acid to assess cell proliferation and to evaluate the expression of HLA class I molecules on cell surface by flow cytometry. Primary cervical tumors of five HLA-A*0201 allele patients were typed for HPV and their CTLs stimulated in vitro with the T2 cell line previously loaded with $50 \mu \mathrm{M}$ of the HPV peptides. Cytotoxicity of stimulated CTLs was assayed against Caski and MS751 cells pretreated with hydralazine and valproic acid.

\section{Results}

The combination of HV acid had antiproliferative effect in $\mathrm{C} 33$ and CasKi cells. VA and VA+H up-regulated the constitutive HLA class I expression as evaluated by flow cytometry. In addition, the antigenic immune recognition of CaSki and MS751 cells by CTLs specific to HPV-16/18 E6 and E7-derived epitopes, was more prominent on cells treated with VA or $\mathrm{H}+\mathrm{VA}$ than cells treated with either $\mathrm{H}$ or IFN- $\gamma$.

\section{Conclusion}

These results support the potential use of $\mathrm{H}$ and VA as an adjunt for immune intervention in cervical cancer patients whenever clinical protocols based on tumor antigen recognition is desirable, such as in those cases where the application of E6 and E7 based therapeutic vaccines is used. 